\title{
Failure to observe learned helplessness in rats exposed to inescapable footshock
}

\author{
WILLIAM W. BEATTY \\ North Dakota State University, Fargo, North Dakota 58105
}

\begin{abstract}
Two experiments were performed to determine whether exposure to inescapable footshock would impair acquisition of difficult (FR 3 or higher) instrumental escape responses by rats. In the first experiment, rats received 250 trials of inescapable or escapable shock (mean duration: $7.7 \mathrm{sec} /$ trial). In the second experiment, animals were exposed to durations of 5,10 , or $20 \mathrm{sec} /$ trial of inescapable footshock. No evidence of an interference effect (helplessness) was observed, despite the use of conditions that should have detected this effect.
\end{abstract}

In recent years, much, theoretical and empirical attention has been devoted to the phenomenon of "learned helplessness," operationally defined as the failure of animals to learn instrumental escape responses after prior exposure to uncontrollable and unpredictable aversive events. Helplessness (or helplessness-like effects) has been reported in many species, but it has been difficult to obtain such effects in the laboratory rat (see Maier \& Seligman, 1976). Recently, several investigators have reported that helplessness can be obtained in the rat, provided a sufficiently difficult instrumental response is used in the escape testing (e.g., Maier, Albin, \& Testa, 1973; Seligman \& Beagley, 1975). In addition to using difficult test responses, these investigators and others who have obtained impaired escape behavior (e.g., Glazer \& Weiss, 1976; Kelsey, 1977) have generally administered inescapable shock either to the rat's tail or through a back electrode. Tail shock requires restraint that may intensify the aversive aspects of the shock (e.g., Bracewell \& Black, 1974) and, with the type of back electrode used by Seligman's group, the rat might learn to control the uncontrollable shock by rolling on its back, shorting out the shock source. Such a response would be incompatible with the instrumental escape response.

In the present experiments, I sought to induce helplessness using exposure to uncontrollable footshock.

\section{EXPERIMENT 1}

\section{Method}

The animals were 18 female and 17 male experimentally naive retired breeders of the Holtzman strain that were caged singly with free access to food and water in a temperaturecontrolled animal room that was illuminated from $0900-2100 \mathrm{~h}$. The rats were assigned at random to groups that received escapable (E) or inescapable (I) shock or no shock treatment (NS) $(\mathrm{N}=5-6$ per sex). Exposure to $\mathrm{E}$ or I shock occurred in one of two identical Lafayette 85200 escape-avoidance chambers. Scrambled ac shock $(1 \mathrm{~mA})$ was delivered to the grid

I thank William Maki, Jerry Holzer, Eric Abraham, and Cathy Hill for excellent technical assistance. floor from a Grason Stadler E 700 source. Preliminary studies indicated that rats escaped from footshock in less than $3 \mathrm{sec}$ in this apparatus, a duration that may be too short to interfere with instrumental escape when presented noncontingently (Glazer \& Weiss, 1976). Accordingly, conditions were arranged so that escape was prevented for $5 \mathrm{sec}$ after the onset of shock at the start of each trial. Then, the motor-driven wall controlling access to the shelf was retracted in the chamber occupied by the rat in the $E$ condition. Shock continued until this rat escaped by climbing onto the shelf that terminated shock for the rat in the $\mathrm{E}$ condition and its yoked partner in the I condition. Rats in both the $\mathrm{E}$ and $\mathrm{I}$ conditions received 50 such trials per day presented on a VT 60 -sec schedule for 5 consecutive days. Average duration of shock received was $7.7 \mathrm{sec} /$ trial.

Approximately $24 \mathrm{~h}$ after the last pretraining session, the rats were tested for instrumental escape responding. Tests were conducted in LVE 143-22 operant conditioning chambers from which the food cup and the right side lever had been removed. Each animal received 20 trials presented on an FT $60-\mathrm{sec}$ schedule. Scrambled ac shock (1 mA) was delivered from a Grason Stadler E 700 source to the grid floor until the rat met the FR barpress requirement or $60 \mathrm{sec}$ elapsed. Pilot data suggested that, under our conditions, FR 4 was the most stringent schedule that untreated males could meet, while FR 8 was the most stringent schedule that untreated females could attain; hence, these differential response requirements were imposed. Conventional electromechanical circuitry controlled experimental events and recorded performance.

\section{Results}

Table 1 presents the results separately for males and females. As seen in the table, males in both the $\mathrm{E}$ and I conditions performed quite competently; the typical (median) animal escaped on all 20 trials, and there was no suggestion of a difference in escape latency. Four of

Table 1

Median Performance in Experiment 1

\begin{tabular}{lcccccccc}
\hline & \multicolumn{3}{c}{$\begin{array}{c}\text { Number of } \\
\text { Escape Failures }\end{array}$} & & \multicolumn{3}{c}{$\begin{array}{c}\text { Escape Latencies } \\
\text { (in Seconds) }\end{array}$} \\
\cline { 2 - 5 } \cline { 6 - 8 } & I & E & NS & & I & E & NS \\
\hline Males & 0.0 & 0 & 0 & & 6.4 & 6.3 & 8.7 \\
Females & 8.5 & 0 & 0 & & 35.8 & 16.6 & 14.5 \\
\hline
\end{tabular}

Note-I=inescapable shock condition; E = escapable shock condition; $N S=$ no-shock condition. 
the five males in the untreated group escaped on all 20 trials, but the remaining animal made only two escapes; consequently, the average escape latency for this group was higher than for the other two groups.

Ostensibly, the data from females revealed quite a different picture. Animals in the NS and E conditions displayed nearly perfect performance in the instrumental escape tests, but three of the six females in the I condition managed a median of only two escapes; the other three females escaped on all 20 trials. I retested the three animals that performed poorly on the initial tests $24 \mathrm{~h}$ later, and their performance improved to 16, 20, and 20 escape responses, respectively. Thus, under conditions that were designed to maximize the disruptive effect of exposure to inescapable shock, I observed at most a transient impairment in some female rats and no deficit at all in males.

\section{EXPERIMENT 2}

Because the duration of exposure to shock on each trial is a critical variable for the induction of negative transfer effects when tail shock of moderate intensity is used (Glazer \& Weiss, 1976), in Experiment 2 I examined the possibility that a longer duration of shock exposure than that delivered in Experiment 1 is required to produce deficits in escape behavior when shock is delivered to the feet.

\section{Method}

The animals were 36 experimentally naive males obtained from the Holtzman Company at approximately 4 months of age. Maintenance procedures were identical to those of Experiment 1 . The rats were assigned randomly to groups of nine animals each that recceived $0,5,10$, or $20 \mathrm{sec} 1$-mA shocks during pretraining. All rats in the shocked groups received $500 \mathrm{sec}$ of inescapable shock on each of 2 consecutive days. Rats in the $5-\mathrm{sec}$ group received 100 trials/day with an ITI of $30 \mathrm{sec}$. Animals in the 10-sec group received 50 trials/day with an ITI of $60 \mathrm{sec}$. Rats in the 20-sec group received 25 trials/day with an ITI of $120 \mathrm{sec}$. Animals in the 0 -sec group received no treatment in pretraining. On the following day, all rats received 20 trials of instrumental escape responding that employed procedures identical to those described in Experiment 1, except the ITI was a VT $60 \mathrm{sec}$, and the ratio requirement for escape was reduced to FR 3. An ADS $1800 \mathrm{E}$ computer controlled events and registered performance.

\section{Results}

As seen in Table 2, nearly all animals in each of the groups exhibited reasonably proficient escape responding (i.e., 13-20 escapes); statistical analysis failed to disclose any effect of shock treatment on either the number of escapes performed or the average escape latency (both Fs $<2$ ). Three rats, one in the 10-sec group and two in the 20 -sec group, performed poorly on the initial test $(6,2$, and 8 escapes, respectively), but when these animals were retested on the following day, performance improved to 17, 20, and 12 escapes, respectively. Thus, the present results revealed transitory
Table 2

Mean Performance in Experiment 2

\begin{tabular}{ccc}
\hline $\begin{array}{c}\text { Shock Duration } \\
\text { (in Seconds) }\end{array}$ & $\begin{array}{c}\text { Number of } \\
\text { Escape Failures }\end{array}$ & $\begin{array}{c}\text { Escape Latency } \\
\text { (in Seconds) }\end{array}$ \\
\hline 0 & 1.5 & 15.7 \\
5 & 1.4 & 13.6 \\
10 & 3.2 & 22.4 \\
20 & 4.4 & 19.8 \\
\hline
\end{tabular}

disruption of instrumental escape responding after exposure to inescapable shock in 3 of 27 animals.

\section{DISCUSSION}

Despite attempts to maximize the sensitivity of the test conditions while employing a suitably difficult escape response, I observed only transient impairments in the escape performance of a few subjects after exposure to inescapable footshock. The rapid improvement in performance of these animals on the following day without any "therapeutic" intervention compels the conclusion that even these initially impaired animals did not display symptoms of helplessness. Of course, it is possible that a longer duration of exposure to inescapable shock would have produced impaired escape behavior, but in the present experiment, both the number of trials and the duration of shock per trial were well in excess of what is required to produce interference effects by prior exposure to inescapable tail shock or back shock (e.g., Glazer \& Weiss, 1976; Maier et al., 1973; Seligman \& Beagley, 1975).

In other experiments, I have attempted to produce helplessness using back shock to rats fitted with electrodes that precluded the possibility that the animal could short out the shock source by rolling on its back. The results were similarly negative, although escape performance under our conditions was so variable that the negative results were not definitive. Moreover, while there have been several recent reports that exposure to inescapable tail shock induced impairments in instrumental escape performance (e.g., Glazer \& Weiss, 1976; Kelsey, 1977; Maier et al., 1973), there is also at least one published failure to observe such an effect (Freda \& Klein, 1976). Thus, the generality of the helplessness effect in the rat remains in doubt.

\section{REFERENCES}

Bracewell, R. J., \& Black, A. H. The effects of restraint and noncontingent pre-shock on subsequent escape learning in the rat. Learning and Motivation, 1974, 5, 53-69.

Freda, J. S., \& Klein, S. B. Generality of the failure-to-escape (helplessness) phenomenon in rats. Animal Learning \& Behavior. 1976, 4, 401-406.

Glazer, H. I., \& Weiss, J. M. Long-term and transitory interference effects. Journal of Experimental Psychology: Animal Behavior Processes, 1976, 2, 191-201.

KELSEY, J. E. Escape acquisition following inescapable shock in the rat. Animal Learning \& Behavior, 1977, 5, 83-92.

Maier, S. F., Albin, R. W., \& Testa, T. J. Failure to learn to escape in rats previously exposed to inescapable shock depends on the nature of escape response. Journal of Comparative and Physiological Psychology, 1973, 85, 581-592.

Maier, S. F., \& Seligman, M. E. P. Learned helplessness: Theory and evidence. Journal of Experimental Psychology: General, 1976, 105, 3-46.

Seligman, M. E. P., \& Beagley, G. Learned helplessness in the rat. Journal of Comparative and Physiological Psychology, 1975, 88, 534-541.

(Received for publication January 3, 1979.) 